\title{
Role of IFN-gamma in immune responses to Candida albicans infections
}

\author{
Daniel Gozalbo ${ }^{1}$, Victoria Maneu², María Luisa Gil ${ }^{1}$ \\ ${ }^{1}$ Departamento de Microbiología y Ecología, Universitat de València, 46100 Burjassot, Valencia, Spain, ${ }^{2}$ Departamento de \\ Optica, Farmacología y Anatomía, Universidad de Alicante, 03690 San Vicente del Raspeig, Alicante, Spain
}

\section{TABLE OF CONTENTS}

1. Abstract

2. Introduction

3. Interferon-gamma (IFN- $\gamma)$

4. IFN- $\gamma$ in Candida albicans infections

4.1. IFN- $\gamma$ is essential for host defense against invasive candidiasis

4.2. IFN- $\gamma$ production by $N K$ cells

4.3. IFN- $\gamma$ production by Th1/Th17 cells

5. Perspective

4.4. IFN- $\gamma$ production by $\gamma \delta$ T cells, NKTcells and CD8 T cells

6. Acknowledgements

7. References

\section{ABSTRACT}

Candida albicans is the most frequent etiologic agent that causes opportunistic fungal infections called candidiasis, a disease whose systemic manifestation could prove fatal and whose incidence is increasing as a result of an expanding immunocompromised population. Here we review the role of interferon-gamma (IFN- $\gamma$ ) in host protection against invasive candidiasis. This cytokine plays an essential role in both the innate and adaptive arms of the immune response to candidiasis. We focus on recent progress on host-pathogen interactions leading to the production of IFN- $\gamma$ by host cells. IFN- $\gamma$ is produced by CD4 Th1, CD8, $\gamma \delta \mathrm{T}$, and natural killer (NK) cells, essentially in response to both IL-12 and/or IL-18; more recently, a subset of C. albicans-specific Th17 cells have been described to produce both IL-17 and IFN- $\gamma$. IFN- $\gamma$ plays an important role in the regulation of the immune system as well as in the control of the infectious process, as it is required for optimal activation of phagocytes, collaborates in the generation of protective antibody response, and favors the development of a Th1 protective response.

\section{INTRODUCTION}

Candida species are the most frequent cause of mucosal and invasive fungal infections (1-3). The leading cause of candidiasis, Candida albicans, resides as a commensal of the human mucosae and the gastrointestinal tract. In immunocompromised hosts, saprophytic colonization often leads to opportunistic mucosal or life-threatening deep organ infection. A wide range of factors that lead to various degrees of immunosuppression predispose patients to infections by Candida. These factors include a severe underlying disease (i.e. AIDS or leukaemia), impaired phagocytic function (i.e. neutropenia), and exogenous factors (such as wide spectrum antibiotic treatment, i.v. drug use, transplantation medicine, trauma, abdominal surgery). Haematogenous candidiasis is a frequent complication in the treatment of patients with acute leukaemia; oropharyngeal candidiasis, a common mucosal infection, occurs in the majority of AIDS patients, and vaginal candidiasis has been estimated to occur in approximately $75 \%$ of women at least once. Morbidity and mortality rates associated with haematogenous disseminated or invasive candidiasis remain unacceptably high, mainly due to the lack of an early and accurate diagnostic procedure, the limited arsenal of antifungal drugs and the emergence of resistant strains (3-6).

Resistance to candidiasis requires the coordinated action of innate and adaptive immune defenses. The phagocytes, neutrophils and macrophages, can clear the pathogen, and furthermore macrophage activation leads to the release of several key mediators such as proinflammatory cytokines, which are important for protecting the host against disseminated candidasis (6). The specific detection of microbes by macrophages and dendritic cells is mediated by pattern recognition receptors (PRRs), germline-encoded, nonclonal receptors, that recognize microbial structures referred to as microorganism-associated molecular patterns (MAMPs). Phagocytic cells recognize C. albicans by a variety of PRRs including receptors for mannosyl/fucosyl glycoconjugates (CR3, MR, DC-SIGN, galectin-3, dectin-2), receptor for $\beta$-glucan (dectin-1), and Toll-like receptors (TLRs) (711). TLRs are essential PRRs and constitute a family of receptors that mediate recognition of microbial challenges, subsequent inflammatory response and are also regulators of the adaptive responses $(12,13)$.

It is accepted that antifungal CD4+ $\mathrm{T}$ helper 1 (Th1)-mediated responses play a central role in anti-C. albicans defenses, providing control of fungal infectivity through production of IFN- $\gamma$, which is required for optimal activation of phagocytes and for helping in the generation of protective antibody response (6). Interestingly, although protective immunity to C. albicans is mediated by Th1 cells, some Th2 cytokines, such as IL-4 and IL-10, are required for the maintenance of the anti- 
fungal immune protection $(6,14,15)$; in addition, regulatory T cells (Treg), activated by IL-10 producing dendritic cells, are involved in the induction of memory protective immunity by negative regulation of antifungal Th1 reactivity (16). More recently, it has been shown that Th17 cell activation also occurs in fungal infections and Th17 cell pathway plays an important regulatory function in promoting protective immunoresponses, particularly in mucocutaenous candidiasis $(6,17,18)$.

Moreover, the immune system must tolerate colonization with commensal fungi (the mycobiome) but defends against fungal invasion; when this balance is disrupted (for example by immunosupression) life-threatening fungal infections develop (19). Moreover, in addition to the host status, the pathogenicity of the fungus also depends on a set of virulence factors (adhesins, hydrolytic enzymes and morphological transition from yeast to hyphal form) whose expression is often environmentally regulated (20). Commensal $C$. albicans cells exhibit the yeast morphology, whereas the yeast to hyphal transition occurs when fungus invades target organs, and the immune system can distinguish these fungal forms through distinct PRRs, promoting different Th lineage development $(8,18,21)$.

Here we review the role of IFN- $\gamma$ in the host protection against invasive candidiasis and focus on recent progress on host-pathogen interactions at the molecular level leading to the production of IFN- $\gamma$ by host cells.

\section{INTERFERON-GAMMA}

Immune, type II interferon, or interferon-gamma (IFN- $\gamma$ ), is a pleiotropic cytokine secreted by CD4 Th1, CD8, $\gamma \delta$ T, and natural killer (NK) cells. Although originally defined as an agent with direct antiviral activity (22), the properties of IFN- $\gamma$ include regulation of the immune system and the control of infectious disease. This cytokine plays an essential role in both the innate and adaptive phases of an immune response $(23,24)$.

Human as well as mouse IFN- $\gamma$ is encoded by a single-copy gene, generating a single 1.2.-kb mRNA-species and a polypeptide of 166 residues containing a cleaved hydrophobic signal sequence of 23 residues. Biologically active IFN- $\gamma$ is in the form of a noncovalent 34-kDa homodimer. IFN- $\gamma$ exerts its effects by binding to the IFN- $\gamma$ receptor, composed of the IFN- $\gamma$ R1 and R2 chains, present on many lymphoid and nonlymphoid cell types (23). IFN- $\gamma$ R complex utilizes the JAK/STAT signal pathway, specifically the receptor-associated Janus-family protein kinases Jak1 and Jak2. Upon ligand binding these kinases are activated, causing the phosphorylation, dimerization, and nuclear translocation of the Stat1 transcription factor (25). The signal transduction pathway stemming from IFN- $\gamma$ is well established, but the manner in which IFN- $\gamma$-induced genes mediate this cytokine's pleotropic functions remains unclear. Over 200 genes are known to be regulated by IFN- $\gamma$ and several IFN- $\gamma$-regulated genes are themselves components of transcription factors. Additionally, IFN- $\gamma$ exerts its effect on a wide variety of cell types owing to the broad expression pattern of the IFN- $\gamma \mathrm{R}$ complex. Thus, determination of the cell types and gene products mediating IFN- $\gamma$ 's in vivo effects remains difficult.

Il is well established that one essential role of IFN- $\gamma$ is to activate a number of phagocytic cell functions, including induction of superoxide formation, upregulation of surface molecule display (e.g. major histocompatibility complex (MHC) class II, Fc $\gamma \mathrm{R}$, integrins), reduction of phagocytic vacuole $\mathrm{pH}$, degradation of intracellular tryptophan, and enhanced killing of intracellular parasites (23). Mice deficient in either IFN- $\gamma$, or IFN- $\gamma$ R1, or IFN- $\gamma$ R2, or the signalling molecule Stat1 have severely impaired immune responses in vivo, as demonstrated by their increased susceptibility to microbial pathogens and certain viruses (26). Besides, humans with mutations in components of the IFN- $\gamma$ receptor-signalling pathway have been identified. Such individuals have profound immunodeficiencies, particularly to intracellular microbial infections, with some individuals dying in early childhood as a consequence of mycobacterial infections (26).

\section{INTERFERON-GAMMA IN Candida albicans INFECTIONS}

\subsection{IFN- $\gamma$ is essential for host defense against invasive candidiasis}

The important role of IFN- $\gamma$ in the resistance against invasive candidiasis has been clearly demonstrated several years ago. Knockout mice deficient in either IFN- $\gamma$ or IFN- $\gamma$ receptor were more susceptible than wild-type mice to invasive $C$. albicans infection (27-29). These reports demonstrated (i) that IFN- $\gamma$ is required for development of protective Th1-dependent immunity $(27,28)$, (ii) that IFN- $\gamma$ knockout mice produce $C$. albicans specific immunoglobulins in lower titers than control mice, and (iii) that peritoneal macrophages from these mice have an impaired nitric oxide production (29). The administration of IFN- $\gamma$ to mice infected with $C$. albicans showed a beneficial effect on the outcome of the infection (30), whereas the injection of a monoclonal antibody to IFN- $\gamma$ resulted in the development of a nonprotective Th2 rather than a protective Th1 response (31). Recent experiments show that concanavalin-A injected to mice allows the survival after a lethal dose of $C$. albicans, probably by promoting Th1 and Th17 responses and therefore IFN- $\gamma$ and IL-17 production (32).

Several mechanisms have been shown to mediate the protective effect of IFN- $\gamma$ against $C$. albicans infections. Early in vitro studies demonstrated stimulatory effects of IFN- $\gamma$ on the phagocytosis and killing of C. albicans by neutrophils and macrophages (33, 34). Exposure of adult macrophages to IFN- $\gamma$ resulted in increased phagocytosis and killing of C. albicans (34); however, no enhancement with cord macrophages could be detected under the same experimental conditions (35). These 
data suggested that neonatal macrophages have a normal capacity to ingest and kill Candida but cannot be fully activated by IFN$\gamma$, a finding that could not be attributed to lower expression or binding of IFN- $\gamma$ receptor to its ligand on neonatal cells. Remarkably, a significantly decreased Stat-1 phosphorylation was detected in neonatal cells in response to IFN- $\gamma$, suggesting the possible existence of a negative regulation of IFN- $\gamma$ receptor signaling in newborns (35).

More recently, mutations in the STAT1 gene have been related to chronic mucocutaneous candidiasis, a chronic disease characterized by persistent symptomatic infection of the nails, skin and mucosa mostly by $C$. albicans. These mutations lead to defective Th1 and Th17 responses characterized by reduced production of IFN- $\gamma$, IL-17 and IL-32, which may explain the higher susceptibility to fungal infections, although the IFN- $\gamma$ receptor pathway was intact in these patients (36).

Oral mucosa is the first line of defense by acting as a physical barrier against $C$. albicans. In an experimental model of oral infection, C. albicans significantly decreased E-cadherin mRNA expression and protein production (37). E-cadherin is a structural protein that maintains a continous epithelial cell attachment, and supports the structural barrier against injurious agents passing through the oral cavity. By decreasing its expression levels, C. albicans facilitates invasion. In this experimental model, IFN- $\gamma$ did specifically prevent the effect of $C$. albicans on E-cadherin gene expression, suggesting a E-cadherin-mediated IFN- $\gamma$ role in anti-candidal defense mechanisms at the epithelial level (37).

Interestingly, C. albicans cells did not activate NADPH oxidase in dendritic cells (DCs) and were poorly killed by these cells; however, the C. albicans killing activity increased upon treatment of DCs with IFN- $\gamma$, indicating that IFN- $\gamma$ probably modulates NADPH oxidase activity, the enzyme responsible for ROS production (38).

Furthermore, the IFN- $\gamma$ induced by the fungus during experimental candidiasis acts on the metabolic pathway involved in tryptophan catabolism by mediating the activation of the indoleamine 2,3-dioxygenase enzyme (IDO) in neutrophils and dendritic cells at the sites of infection. IDO activation in neutrophils leads to the activation of the killing machinery while sparing the inflammatory response, whereas in dendritic cells results in tipping the balance between IL-12 and IL-10 production leading to Th1 and Treg-mediated protective immunity. IDO blockade by an enzyme inhibitor exacerbates the infection process as well as the associated inflammatory pathology, and in addition, abolishes resistance to reinfection caused by deregulated innate and adaptive immune responses. Therefore, IDO activation represents one of the mechanisms by which IFN- $\gamma$ exerts a fine control on the inflammatory and adaptive antifungal responses $(6,39,40)$.

The development of vaccines against C. albicans have shown that protective adaptive immunity against fungal infections is mediated by Th1-Th17 cells, through an increase in IFN- $\gamma$ and IL-17, both in laboratory experiments and in clinical trials (41-44). Therefore, it has been suggested that different preparations/extracts should be analyzed in order to choose those that induce greater levels of IFN- $\gamma$ for the development of new vaccines (45).

\subsection{IFN- $\gamma$ production by NK cells}

A crucial step in the control of intracellular pathogens is the early production of IFN- $\gamma$ by NK cells. NK cells are an essential component of the innate immune response and are recruited to the site of infection within minutes following pathogen invasion. At the site of infection, and as a consequence of interacting with various microbial products, macrophages and dendritic cells produce proinflammatory cytokines (TNF- $\alpha$, IL-12, IL-15 and IL-18), which bind to their receptors on NK cells, leading to their activation and to the rapid production and secretion of IFN- $\gamma$. This IFN- $\gamma$ produced by NK cells not only serves as a first line of defense against invading pathogens, but may also contribute to the induction of the appropriate adaptive immune response. Moreover, the expression of TLRs on NK cells has been reported and several data indicate that NK cells can directly recognize and respond to pathogen components through TLRs by secreting IFN- $\gamma(46-51)$. However, controversies remain regarding the TLR expression in NK cells and their responsiveness to agonists, particularly the requirement for the presence of accessory cells, such as dendritic cells, or accessory cytokines to respond to TLR agonists (52).

Interaction of lymphokine activated killer (LAK) cells with C. albicans does not inhibit or kill the fungal pathogen by means of the LAK lytic machinery, but through secretion of cytokines which have stimulatory effects on phagocytic cells (53). Therefore, the antifungal immunity mediated by NK cells appears to occur by secretion of cytokines that activate phagocytic cells, although whether NK cells are stimulated directly by the fungus or indirectly in response to signals generated by activated bystander host cells was not clearly established (53-55). Recent studies have shown that cytokine-primed human NK cells are activated by direct contact with $C$. albicans following actin-dependent engulfment of fungal cells; this NK cell activation results in degranulation and the release of granulocyte-macrophage colony stimulating factor, IFN- $\gamma$ and TNF- $\alpha$, and induces fungal damage (56). It should be noted that NK cells are unable to inhibit filamentation of engulfed C. albicans, and that antifungal activity of NK cells is mainly attributed to secreted perforin (56).

Interestingly, when the role of TLRs in triggering IFN- $\gamma$ secretion by NK cells in response to yeasts and hyphae of $C$. albicans was studied, it was unexpectedly found that fungal cells cause an inhibition of IFN- $\gamma$ secretion by murine NK cells. Killed yeasts and hyphae of $C$. albicans inhibited IFN- $\gamma$ secretion by highly purified murine NK cells in response to TLR4 and TLR2 ligands, LPS and zymosan, respectively, and this effect was also observed in the presence of NK activating cytokines (IL- 
2, IL-12 and IL-15) (57). Since the role of NK cells in resistance to C. albicans appears to be basically mediated by cytokine production (including IFN- $\gamma$ ) that activates phagocytic cells $(34,53)$, its inhibition by $C$. albicans may favor the survival of the pathogen. Besides, this inhibitory effect may also: (i) inhibit IFN- $\gamma$ production by NK cells in response to cytokines secreted by activated bystander cells (48), and (ii) disturb the crosstalk between NK and dendritic cells, as the IFN- $\gamma$ secreted by NK cells controls dendritic cell maturation and their $\mathrm{T}$ cell stimulatory activity $(58,59)$. This finding suggests a mechanism of immune evasion, based on inhibition of NK cells, which may contribute to the virulence of $C$. albicans.

\subsection{IFN- $\gamma$ production by Th1 cells}

The inflammatory environment established by the innate response influences the adaptive immune response: activation, expansion, and selection of pathogen-specific lymphocytes. Besides cell-cell contacts that provide activation signals via peptideMHC class II/TCR and classical costimulatory interactions (B7/CD28), antigen presenting cells (APCs) communicate with T cells via cytokine production, which is responsible for the expansion and differentiation of naïve $\mathrm{T}$ cells to generate mature phenotype, such as Th1 and Th2 cells. Th1 cells secrete IFN- $\gamma$, IL-2, TNF- $\alpha$ and TNF- $\beta$, whereas Th 2 cells secrete IL-4, IL-5, IL6 , IL-10, and IL-13, and down-regulate Th1 responses. IL-12 is the signature cytokine produced by cells of the innate immune system that influences adaptive cell immunity. IL-12 plays a central role in promoting the differentiation of naïve CD4+ T cells into mature Th1 effector cells and it is a potent stimulus for NK cells and CD8+ T cells to produce IFN- $\gamma$.

It is well established that Th1, and not Th2, response confers protection against candidiasis. The activation of Th1 cells is instrumental (i) in the optimal activation of phagocytes at the sites of infection through the production of IFN- $\gamma$ and (ii) in the help for the generation of opsonizing antibodies $(6,40)$. Th1 cells can exert cross-reactivity among different fungal species, as $C$. albicans and Aspergillus fumigatus, due to the conserved antigen molecules shared by fungi (60).

While the Th1 cytokines IFN- $\gamma$ and TNF- $\alpha$ are required for the successful control of the infection $(6,8,61)$, Th2 cytokines (IL-4 and IL-10) inhibit Th1 development and deactivate phagocytic effector cells. Th1 and Th2 cells derive from common T precursor cells, and they differentiate by the activity of several transcription factors. The transcription factor GATA-3 is recognized as a master regulator for Th2 differentiation and it is likely that GATA-3 is a critical host factor in the determination of susceptibility to systemic Candida infection. Haraguchi et al. (62) demonstrated that overexpression of GATA-3 modulates macrophage antifungal activity and enhances the susceptibility to systemic Candida infection, possibly by reducing the production of IFN- $\gamma$.

The Linker for Activation of B cells/Non-T cell Activating Linker (LAB/NTAL) encoded by Lat2, is a known regulator of ITAM-coupled receptors and TLR-associated cytokine responses (63). Recently, it has been reported that LAB is involved in anti-fungal immunity as Lat $2^{-/}$mice are more susceptible to $C$. albicans infection than wild type mice. Lat2 gene is expressed by dendritic cells and is involved in developing a Th1 response to C. albicans, as Lat $2^{-/-}$dendritic cells showed a reduced Th1 polarization in vitro and Lat $2^{-/-}$mice have a reduced production of IFN- $\gamma(64)$.

Romani et al. $(65,66)$ developed a murine model of systemic candidiasis in which resistance to reinfection with virulent wild-type yeasts is induced by prior exposure of mice to a low-virulence agerminative strain of $C$. albicans. In this experimental model, the development of a protective anticandidal response correlated with the detection of Th1-associated immunity $(66,67)$. Using this model in MyD88 ${ }^{-/-}$mice (which are defective in the adaptor molecule MyD88, which is essential for signal transduction through TLRs except TLR3) (12), it was shown a default of production of Th1 cytokines (IFN- $\gamma$, IL-12, TNF- $\alpha$ ) in these mice, which correlated with a diminished frequency of IFN- $\gamma$ producing CD4+ T lymphocytes and an increased susceptibility to infection (68). These results indicate that TLR/MyD88-dependent inflammatory pathway is essential for the development of a protective Th1 response against $C$. albicans. These observations agree with those reported by Bellocchio et al. (69) showing that MyD88-dependent signalling is crucial for antifungal responses. Since TLR2 and TLR4 have been implicated in anti-Candida responses $(7,10,69,70)$, similar studies were performed in TLR2 ${ }^{-/}$and TLR4 ${ }^{-/-}$mice $(7,8)$. IL-12 could not be detected in TLR2 ${ }^{-/}$mice as opposed to wild type mice, and the IFN- $\gamma$ production was significantly lower in TLR2-/- mice than in control mice in response to both $C$. albicans yeasts and hyphae (71). Moreover, TLR2 ${ }^{-/}$mice showed a lower frequency of Th1 cells than control mice (unpublished results). By contrast, TLR4 ${ }^{-/-}$and C3H/HeJ mice (carrying a mutant TLR4 allele which confers defective TLR4-mediated signalling) showed an IL-12 and IFN- $\gamma$ production similar to their respective control mice and accordingly, a similar frequency of IFN- $\gamma$ producing CD4+ T lymphocytes (72). Therefore, these results indicate that TLR2 is the most important TLR involved in the interaction with $C$. albicans leading to a Th1 protective response, whereas TLR4 appears to be dispensable $(7,8,72)$. However, some discrepancies about the recognition of $C$. albicans by TLR2 and TLR4 and its consequences in host protection against infection have been reported; this is probably due to different experimental approaches and/or the use of different yeast strains, as recognition by TLR4 appears to be strain dependent $(7,8,69,70,73,74)$.

One important advantage of $C$. albicans hyphae appears to be the ability to polarize the adaptative immunity towards a nonprotective Th2 response. Although the mechanism for this effect is not completely understood, some relevant information has been achieved. The most important difference in the secretory response to both fungal morphotypes is the well-documented higher production of IL-12 in response to yeasts, which is accompanied by a Th1 type response. IL-12 production by human blood monocytes, as well as mouse and human dendritic cells, basically occurs in response to the yeast form, whereas a reduced 
IL-12 production is elicited upon exposure to hyphae (75-78). Romani and co-workers observed that dendritic cells pulsed in vitro with yeast and transferred back into mice, stimulated Th1 immune responses, while dendritic cells exposed to fungal filaments induced Th2 responses $(76,78,79)$. On the other hand, it has been demonstrated that dectin-1, a phagocytic receptor for $\beta$-glucan, either alone or in collaboration with TLR2, elicits a strong inflammatory response (enhanced stimulation of TNF- $\alpha$ and IL-12) to yeasts $(80,81)$. It has been shown that dectin-1 mediates in vitro macrophage recognition of $C$. albicans yeasts but not hyphae, since hyphal cells do not appear to expose the $\beta$-glucan at the cell surface, suggesting that failure of hyphae to activate dectin-1 might contribute to an impaired Th1 response $(82,83)$. However, exposure of $\beta$-glucan in yeasts or hyphae surfaces appears to be similar during in vivo infection (84).

The Th1-versus Th2 dichotomy has dominated $\mathrm{T}$ cell biology for many years. However, another $\mathrm{T}$ helper subset, the Th17 lineage that secretes IL-17, has risen to prominence $(17,18,85,86)$. Th17 cell development occurs in the presence of TGF$\beta$ and IL-6 and is opposed by Th1 cytokines. Th17 cells are maintained in the presence of the IL-12-related cytokine IL-23. IL-17 induces chemokine production at the sites of infection and causes recruitment of neutrophils. IL-17 receptor-deficient mice are more susceptible than control mice to systemic candidiasis and this effect may be attributed to a decreased influx of neutrophils to infected organs (85). It has been described that the Th17 pathway do develop in response to C. albicans (87, 88). Although one report suggested that the Th17 pathway acts as negative regulator of the Th1 mediated immune resistance to C. albicans (89), most data are consistent with a protective role of IL-17 in systemic candidemia $(85,90)$ and, in addition, it has been shown that C. albicans-specific Th17 cells produced IFN- $\gamma$ and IL-17 but no IL-10, in a IL-1 $\beta$ mediated manner (42). Furthermore, immunization with a recombinant vaccine causes a Th1, Th17, and Th1/17 mediated protective immunity against $C$. albicans infection in mice, and this response involves CD4+ T-cell-derived IFN- $\gamma$ and IL-17, as well as functional phagocytic effectors (41).

\subsection{IFN- $\gamma$ production by $\gamma \delta$ T cells, NKT cells and CD8 T cells}

A minority of T cells expresses a TCR consisting of $\gamma$ and $\delta$ chains, and those cells are primarily CD4+. These chains are encoded by few genes and accordingly, the $\gamma \delta$ repertoire is very limited. Despite sharing many similarities with $\alpha \beta$ T cells, their method of activation differs markedly as the recognition of antigen by $\gamma \delta \mathrm{T}$ cells may be not MHC-restricted. There are two main population subsets of $\gamma \delta \mathrm{T}$ cells: $\gamma \delta 2 \mathrm{~T}$ cells comprise a very small percentage of circulating lymphocytes, and $\gamma \delta 1 \mathrm{~T}$ cells are resident in the mucosal-associated lymphoid tissue $(91,92)$. Although the function of $\gamma \delta \mathrm{T}$ cells appears to be dependent on several factors, including tissue distribution, local microenvironment, and stage of the immune response, one attribute of these cells is the production of IFN- $\gamma$ upon activation. It was early shown that the $\gamma \delta \mathrm{T}$ cells enhance macrophage nitric oxide production and anti-Candida activity in vitro (93). $\gamma \delta \mathrm{T}$ cells may contribute to immunosurveillance at the body surface, as mice deficient in $\gamma \delta \mathrm{T}$ cells or depleted in these cells are highly susceptible to orogastric candidiasis (94). $\gamma \delta 1 \mathrm{~T}$ circulating population can proliferate and produce IFN- $\gamma$ and IL-17 in response to C. albicans in vitro, and therefore may play an important role in the defense against infection $(92,95)$.

NKT cells constitute a subset of mature T lymphocytes characterized by the coexpression of $\alpha \beta$ TCR as well as the NK1.1. cell marker. These cells recognize lipids in the context of the nonclassical MHC molecule CD1, and are able to rapidly release vast quantities of diverse effector cytokines, including IFN- $\gamma$. NKT cells play a role in immunity against fungal infections, including candidiasis, probably by IFN- $\gamma$ production and polarization towards Th1 response (96-98). It has been recently reported that coinfection with commensal bacteria, or treatment with bacterial glicolipids, exacerbates systemic C. albicans infection through IFN- $\gamma$ produced in part by NKT cells; the increased levels of IFN- $\gamma$ in the early phase of infection caused a dramatic decrease in the blood and bone marrow neutrophils, suggesting the hypothesis that the timing and quantity of IFN- $\gamma$ determine the effect on neutrophils and other bone marrow cells, and therefore may modulate the fate of fungal infection (99).

$\mathrm{CD}^{+} \mathrm{T}$ cells play a pivotal role in immune responses against many viruses and tumors, and may also contribute to immunity to fungi $(4,100)$. These T cells recognize antigens that are presented on the surface of host cells by MHC class I molecules, leading to their destruction, and therefore are also known as cytotoxic $\mathrm{T}$ cells. The possible role of CD8+ T cells in resistance to candidiasis has been somewhat controversial, although some early reports suggested a role of these cells during infection $(100,101)$. It is accepted that both CD4+ and CD8+ T cells are necessary for elimination of some fungal pathogens; in the primary stages of many fungal diseases the presence of CD4+ T cells is essential for host survival, whereas CD8+ T cells are only necessary to restrict infection $(100,102)$. The main effector mechanisms of CD8+ T cells are cytotoxicity and cytokine secretion (IFN- $\gamma$ ). The role of cytotoxicity in host defense against fungi is not well delineated, whereas the activity of cytokines is better understood. The Th1 cytokine IL-12 is also a potent stimulus for CD8+ T cells to produce IFN- $\gamma$. The frequency of IFN- $\gamma$ producing CD8+ T lymphocytes is diminished in MyD88-deficient mice as compared with wild-type mice, in agreement with the default of production of Th1 cytokines (IFN- $\gamma$, IL-12, TNF- $\alpha$ ) detected in these mice, as well as with their strong susceptibility to candidiasis $(8,68)$.

As a conclusion, CD8, NKT and $\gamma \delta$ T cells may have a role in protection against candidiasis. Probably the major role of these cells is the cytokine production, which is instrumental in mobilizing and activating antifungal effectors, thus providing prompt and effective control of infectivity once the fungus has been established itself in mucosal tissues or spread to internal organs. 


\section{PERSPECTIVE}

The level of our understanding of fungal-host interactions has clearly progressed in the last few years. Although the important role of IFN- $\gamma$ secreting Th1 responses in protection against $C$. albicans infections has been well established several years ago, recently there has raised increasing interest in how adaptive immune responses are controlled by the innate immune system. Researchers have focused on the discovery of PRRs that, upon recognition of MAMPs on fungal cells, initiate adaptive responses through activation and maturation of dendritic cells. Considerably new information has been gained in this field concerning the role of TLRs, dectin-1, galectin-3 and dectin-2, as well as cooperation between dectin-1 and TLR2, although we are far to completely discerning the intricate molecular mechanisms leading to the elicitation of a protective immune response to C. albicans infections.

The discovery of IL-23/Th17 pathway in response to $C$. albicans has represented a significant advance in the field of adaptive immune response. Modulation of this inflammatory Th17 response is a potential target for development of new strategies to stimulate protective immunity to C. albicans. Two types of human Th17 cells with distinct effector function and differentiation requirements have been described; $C$. albicans-specific Th17 cells produced IFN- $\gamma$ and IL-17 but no IL-10, in a IL-1 $\beta$ mediated manner. Therefore, strategies to generate this subpopulation can be of potential interest for anti $C$. albicans immunotherapies (42). It has been shown that immunization with a recombinant vaccine primed Th1, Th17 and Th1/17 lymphocytes, which produced proinflammatory cytokines that enhanced phagocytic killing of Candida (41).

The ultimate objective is to apply our knowledge of how C. albicans stimulates the immune response to improve the therapy of candidiasis and thus the clinical control of fungal infections in the at-risk population. There are several strategies for immunotherapy related to IFN- $\gamma$; one of them is the use of recombinant (r) IFN- $\gamma$ as adjunctive therapeutic. Despite the widespread use of prophylactic rIFN- $\gamma$ in chronic granulomatous disease (a genetic disorder characterized by recurrent bacterial and fungal infections and tissue granuloma formation), invasive fungal infection has remained a persistent problem in these patients (103). However, on the basis of a large volume of other preclinical studies and phase I and II clinical trials (104), adjunctive rIFN- $\gamma$ (in combination with antifungal agents) have been further evaluated, with no relevant advances. Alternatively, the generation of functionally active anti-C. albicans IFN- $\gamma$ secreting $\mathrm{T}$ cells is feasible, and this was suggested as a potential treatment option for patients with candidiasis after alogenic haematopoietic stem-cell transplant (105).

Vaccination strategies against C. albicans components that bias the immune responses towards Th1/17 may represent an effective immunotherapeutic tool (106). For instance, vaccination with recombinant Als3p N-terminal portion protects mice from both systemic and mucosal infections by stimulating peripheral blood mononuclear cell production of both IFN- $\gamma$ and IL17A. This vaccine has been recently tested in a phase I clinical trial with promising results, as it was found to be safe, well tolerated and induced strong humoral and cellular immune responses, with increased IL-17 and IFN- $\gamma$ production (43, 44). Also, new synthetically prepared glycooligosaccharides conjugates mimicking Candida cell wall antigens have been assessed in vivo and in vitro to test their immunobiological efficacy. The conjugates biased the immune responses towards Th1 and Th17, and represent prospective immunobiological components for further immunopharmacologically relevant Candida vaccine design (107).

Finally, it should be noted that recent findings have demonstrated a significant role of type I IFN in host defense against C. albicans. Smeekens et al. (108) have shown that type I IFN has a crucial role in anti-Candida host defense in humans and that type I IFN induced by Candida modulates Th1/Th17 cytokine profiles, with an increase in IFN- $\gamma$ and a decrease in IL-17. Other reports have shown that conventional DCs are able to mount a type I IFN response against C. albicans (109) and that IFN- $\beta$ production by DCs is crucial for immunity to C. albicans (110). Although the precise effect of type I IFNs on anti Candida host defense is still being debated, mechanisms inducing type I IFN production may also represent a target for immunointervention against C. albicans.

\section{ACKNOWLEDEGEMENTS}

Research in the M.L. Gil and D. Gozalbo laboratory is supported by Grant SAF2010-18256 (Ministerio de Economia y Competitividad, Spain).

\section{REFERENCES}

1. W Hope, P Natarajan and L Goodwin: Invasive fungal infections. Clin Med 13, 507-510 (2013)

2. J Kim and P Sudbery: Candida albicans, a major human fungal pathogen. J Microbiol 49, 171-177 (2011)

3. JC Sardi, L Scorzoni, T Bernardi, AM Fusco-Almeida and MJ Mendes Giannini: Candida species: current epidemiology, pathogenicity, biofilm formation, natural antifungal products and new therapeutic options. J Med Microbiol 62, 10-24 (2013) 
4. RA Calderone: Candida and candidiasis. New York: American Society for Microbiology. (2001)

5. MA Pfaller and DJ Diekema: Epidemiology of invasive candidiasis: a persistent public health problem. Clin Microbiol Rev 20, 133-163 (2007)

6. L Romani: Immunity to fungal infections. Nat Rev Immunol 11, 275-288 (2011)

7. ML Gil and D Gozalbo: TLR2, but not TLR4, triggers cytokine production by murine cells in response to Candida albicans yeasts and hyphae. Microbes Infect 8, 2299-2304 (2006)

8. ML Gil and D Gozalbo: Role of Toll-like receptors in systemic Candida albicans infections. Front Biosci 14, 570-582 (2009)

9. HS Goodridge and DM Underhill: Fungal Recognition by TLR2 and Dectin-1. Handb Exp Pharmacol 183, 87-109 (2008)

10. D Poulain and T Jouault: Candida albicans cell wall glycans, host receptors and responses: elements for a decisive crosstalk. Curr Opin Microbiol 7, 342-349 (2004)

11. T Zelante, C Montagnoli, S Bozza, R Gaziano, S Bellocchio, P Bonifazi, S Moretti, F Fallarino, P Puccetti and L Romani: Receptors and pathways in innate antifungal immunity: the implication for tolerance and immunity to fungi. Adv Exp Med Biol 590, 209-221 (2007)

12. T Kawai and S Akira: The role of pattern-recognition receptors in innate immunity: update on Toll-like receptors. Nat Immunol 11, 373-384 (2010)

13. AP West, AA Koblansky and S Ghosh: Recognition and signaling by toll-like receptors. Annu Rev Cell Dev Biol 22, 409-437 (2006)

14. A Mencacci, E Cenci, G Del Sero, C Fe d'Ostiani, P Mosci, G Trinchieri, L Adorini and L Romani: IL-10 is required for development of protective Th1 responses in IL-12-deficient mice upon Candida albicans infection. J Immunol 161, 6228-6237 (1998)

15. A Mencacci, G Del Sero, E Cenci, CF d'Ostiani, A Bacci, C Montagnoli, M Kopf and L Romani: Endogenous interleukin 4 is required for development of protective CD4+ T helper type 1 cell responses to Candida albicans. J Exp Med 187, 307-317 (1998)

16. C Montagnoli, A Bacci, S Bozza, R Gaziano, P Mosci, AH Sharpe and L Romani: B7/CD28-dependent CD4+CD25+ regulatory $\mathrm{T}$ cells are essential components of the memory-protective immunity to Candida albicans. J Immunol 169, 6298-6308 (2002)

17. HR Conti, F Shen, N Nayyar, E Stocum, JN Sun, MJ Lindemann, AW Ho, JH Hai, JJ Yu, JW Jung, SG Filler, P MassoWelch, M Edgerton and SL Gaffen: Th17 cells and IL-17 receptor signaling are essential for mucosal host defense against oral candidiasis. J Exp Med 206, 299-311 (2009)

18. N Hernandez-Santos and SL Gaffen: Th17 cells in immunity to Candida albicans. Cell Host Microbe 11, 425-435 (2012)

19. ID Iliev and DM Underhill: Striking a balance: fungal commensalism versus pathogenesis. Curr Opin Microbiol 16, 366-373 (2013)

20. D Gozalbo, P Roig, E Villamón and ML Gil: Candida and candidiasis: the cell wall as a potential molecular target for antifungal therapy. Curr Drug Targets Infect Disord 4, 117-135 (2004)

21. NA Gow, FL van de Veerdonk, AJ Brown and MG Netea: Candida albicans morphogenesis and host defence: discriminating invasion from colonization. Nat Rev Microbiol 10, 112-122 (2011)

22. EF Wheelock: Interferon-like virus-inhibitor induced in human leukocytes by phytohemagglutinin. Science 149, 310-311 (1965)

23. U Boehm, T Klamp, M Groot and JC Howard: Cellular responses to interferon-gamma. Annu Rev Immunol 15, 749-795 (1997)

24. S Kearney, C Delgado and LL Lenz: Differential effects of type I and II interferons on myeloid cells and resistance to intracellular bacterial infections. Immunol Res 55, 187-200 (2013) 
25. WJ Leonard and JJ O'Shea: Jaks and STATs: biological implications. Annu Rev Immunol 16, 293-322 (1998)

26. SJ Szabo, BM Sullivan, SL Peng and LH Glimcher: Molecular mechanisms regulating Th1 immune responses. Annu Rev Immunol 21, 713-758 (2003)

27. E Balish, RD Wagner, A Vazquez-Torres, C Pierson and T Warner: Candidiasis in interferon-gamma knockout (IFN-gamma ${ }^{-}$ ${ }^{\circ}$ ) mice. J Infect Dis 178, 478-487 (1998)

28. E Cenci, A Mencacci, G Del Sero, CF d'Ostiani, P Mosci, A Bacci, C Montagnoli, M Kopf and L Romani: IFN-gamma is required for IL-12 responsiveness in mice with Candida albicans infection. J Immunol 161, 3543-3550 (1998)

29. R Kaposzta, P Tree, L Marodi and S Gordon: Characteristics of invasive candidiasis in gamma interferon- and interleukin-4deficient mice: role of macrophages in host defense against Candida albicans. Infect Immun 66, 1708-1717 (1998)

30. BJ Kullberg, JW van 't Wout, C Hoogstraten and R van Furth: Recombinant interferon-gamma enhances resistance to acute disseminated Candida albicans infection in mice. J Infect Dis 168, 436-443 (1993)

31. L Romani, E Cenci, A Mencacci, R Spaccapelo, U Grohmann, P Puccetti and F Bistoni: Gamma interferon modifies CD4+ subset expression in murine candidiasis. Infect Immun 60, 4950-4952 (1992)

32. PG de Carvalho, LA Custodio, I Conchon-Costa, C. G. Andrade, G. F. Quirino, R. S. de Almeida and I. Felipe: Concanavalin-A induces IL-17 production during the course of Candida albicans infection. FEMS Immunol Med Microbiol 64, 273-279 (2012)

33. JY Djeu, DK Blanchard, D Halkias and H Friedman: Growth inhibition of Candida albicans by human polymorphonuclear neutrophils: activation by interferon-gamma and tumor necrosis factor. J Immunol 137, 2980-2984 (1986)

34. L Marodi, S Schreiber, DC Anderson, RP MacDermott, HM Korchak and RB Johnston, Jr.: Enhancement of macrophage candidacidal activity by interferon-gamma. Increased phagocytosis, killing, and calcium signal mediated by a decreased number of mannose receptors. J Clin Invest 91, 2596-2601 (1993)

35. L Marodi: Deficient interferon-gamma receptor-mediated signaling in neonatal macrophages. Acta Paediatr Suppl 91, 117$119(2002)$

36. FL van de Veerdonk, TS Plantinga, A Hoischen, SP Smeekens, LA Joosten, C Gilissen, P Arts, DC Rosentul, AJ Carmichael, CA Smits-van der Graaf, BJ Kullberg, JW van der Meer, D Lilic, JA Veltman and MG Netea: STAT1 mutations in autosomal dominant chronic mucocutaneous candidiasis. N Engl J Med 365, 54-61 (2011)

37. M Rouabhia, A Semlali, J Audoy and W Chmielewski: Antagonistic effect of Candida albicans and IFNgamma on Ecadherin expression and production by human primary gingival epithelial cells. Cell Immunol 280, 61-67 (2012)

38. M Donini, E Zenaro, N Tamassia and S Dusi: NADPH oxidase of human dendritic cells: role in Candida albicans killing and regulation by interferons, dectin-1 and CD206. Eur J Immunol 37, 1194-1203 (2007)

39. S Bozza, F Fallarino, L Pitzurra, T Zelante, C Montagnoli, S Bellocchio, P Mosci, C Vacca, P Puccetti and L Romani: A crucial role for tryptophan catabolism at the host/Candida albicans interface. J Immunol 174, 2910-2918 (2005)

40. L Romani and P Puccetti: Protective tolerance to fungi: the role of IL-10 and tryptophan catabolism. Trends Microbiol 14, 183-189 (2006)

41. L Lin, AS Ibrahim, X Xu, JM Farber, V Avanesian, B.Baquir, Y Fu, SW French, JE Edwards, Jr. and B Spellberg: Th1-Th17 cells mediate protective adaptive immunity against Staphylococcus aureus and Candida albicans infection in mice. PLoS Pathog 5, e1000703 (2009)

42. CE Zielinski, F Mele, D Aschenbrenner, D Jarrossay, F Ronchi, M Gattorno, S Monticelli, A Lanzavecchia and F Sallusto: Pathogen-induced human TH17 cells produce IFN-gamma or IL-10 and are regulated by IL-1beta. Nature 484, $514-518$ (2012)

43. CS Schmidt, CJ White, AS Ibrahim, SG Filler, Y Fu, MR Yeaman, JE Edwards, Jr. and JP Hennessey, Jr.: NDV-3, a recombinant alum-adjuvanted vaccine for Candida and Staphylococcus aureus, is safe and immunogenic in healthy adults. Vaccine 30, 7594-7600 (2012) 
44. AS Ibrahim, G Luo, T Gebremariam, H Lee, CS Schmidt, JP Hennessey, Jr., SW French, MR Yeaman, SG Filler and JE Edwards, Jr.: NDV-3 protects mice from vulvovaginal candidiasis through T- and B-cell immune response. Vaccine 31, 55495556 (2013)

45. K Ranta, K Nieminen, T Saariaho, O Kortekangas-Savolainen, EK Kumpula, J Kosonen, AL. Pasanen and J. Savolainen: Evaluation of fungal extracts to determine immunomodulatory properties. J Investig Allergol Clin Immunol 23, 226-233 (2013)

46. I Becker, N Salaiza, M Aguirre, J Delgado, N Carrillo-Carrasco, LG Kobeh, A Ruiz, R Cervantes, AP Torres, N Cabrera, A. Gonzalez, C Maldonado and A Isibasi: Leishmania lipophosphoglycan (LPG) activates NK cells through toll-like receptor-2. Mol Biochem Parasitol 130, 65-74 (2003)

47. A Chalifour, P. Jeannin, JF Gauchat, A Blaecke, M Malissard, T N'Guyen, N Thieblemont and Y Delneste: Direct bacterial protein PAMP recognition by human NK cells involves TLRs and triggers alpha-defensin production. Blood 104, 1778-1783 (2004)

48. OM Hart, V Athie-Morales, GM O'Connor and CM Gardiner: TLR7/8-mediated activation of human NK cells results in accessory cell-dependent IFN-gamma production. J Immunol 175, 1636-1642 (2005)

49. V Hornung, S Rothenfusser, S Britsch, A Krug, B Jahrsdorfer, T Giese, S Endres and G Hartmann: Quantitative expression of toll-like receptor 1-10 mRNA in cellular subsets of human peripheral blood mononuclear cells and sensitivity to CpG oligodeoxynucleotides. J Immunol 168, 4531-4537 (2002)

50. J Sawaki, H Tsutsui, N Hayashi, K Yasuda, S Akira, T Tanizawa and K Nakanishi: Type 1 cytokine/chemokine production by mouse NK cells following activation of their TLR/MyD88-mediated pathways. Int Immunol 19, 311-320 (2007)

51. S Sivori, M Falco, M Della Chiesa, S Carlomagno, M Vitale, L Moretta and A Moretta: CpG and double-stranded RNA trigger human NK cells by Toll-like receptors: induction of cytokine release and cytotoxicity against tumors and dendritic cells. Proc Natl Acad Sci USA 101, 10116-10121 (2004)

52. M Adib-Conquy, D Scott-Algara, JM Cavaillon and F Souza-Fonseca-Guimaraes: TLR-mediated activation of NK cells and their role in bacterial/viral immune responses in mammals. Immunol Cell Biol 92, 256-252 (2014)

53. G Arancia, A Stringaro, P Crateri, A Torosantucci, C Ramoni, F. Urbani, CM Ausiello and A Cassone: Interaction between human interleukin-2-activated natural killer cells and heat-killed germ tube forms of Candida albicans. Cell Immunol 186, 28-38 (1998)

54. P Tran, R Ahmad, J Xu, A Ahmad and J Menezes: Host's innate immune response to fungal and bacterial agents in vitro: upregulation of interleukin-15 gene expression resulting in enhanced natural killer cell activity. Immunology 109, 263-270 (2003)

55. I Algarra, E Ortega, MJ Serrano, G Alvarez de Cienfuegos and JJ Gaforio: Suppression of splenic macrophage Candida albicans phagocytosis following in vivo depletion of natural killer cells in immunocompetent BALB/c mice and T-cell-deficient nude mice. FEMS Immunol Med Microbiol 33, 159-163 (2002)

56. J Voigt, K Hunniger, M Bouzani, ID Jacobsen, D.Barz, B Hube, J Loffler and O Kurzai: Human Natural Killer Cells Acting as Phagocytes Against Candida albicans and Mounting an Inflammatory Response That Modulates Neutrophil Antifungal Activity. J Infect Dis 209, 616-626 (2014)

57. C Murciano, E Villamon, JE O'Connor, D Gozalbo and ML Gil: Killed Candida albicans yeasts and hyphae inhibit gamma interferon release by murine natural killer cells. Infect Immun 74, 1403-1406 (2006)

58. MA Degli-Esposti and MJ Smyth: Close encounters of different kinds: dendritic cells and NK cells take centre stage. Nat Rev Immunol 5, 112-124 (2005)

59. M Della Chiesa, S Sivori, R Castriconi, E Marcenaro and A Moretta: Pathogen-induced private conversations between natural killer and dendritic cells. Trends Microbiol 13, 128-136 (2005)

60. C Stuehler, N Khanna, S Bozza, T Zelante, S Moretti, M Kruhm, S Lurati, B Conrad, E Worschech, S Stevanovic, S Krappmann, H Einsele, JP Latge, J Loeffler, L Romani and MS Topp: Cross-protective TH1 immunity against Aspergillus fumigatus and Candida albicans. Blood 117, 5881-5891 (2011)

61. L Romani: Immunity to Candida albicans: Th1, Th2 cells and beyond. Curr Opin Microbiol 2, 363-367 (1999) 
62. N Haraguchi, Y Ishii, Y Morishima, K Yoh, Y Matsuno, N Kikuchi, T Sakamoto, S Takahashi and N Hizawa: Impairment of host defense against disseminated candidiasis in mice overexpressing GATA-3. Infect Immun 78, 2302-2311 (2010)

63. SJ. Orr and DW McVicar: LAB/NTAL/Lat2: a force to be reckoned with in all leukocytes? J Leukoc Biol 89, 11-19 (2011)

64. SJ Orr, AR Burg, T Chan, L Quigley, GW Jones, JW Ford, D Hodge, C Razzook, J Sarhan, YL Jones, GC Whittaker, KC Boelte, L Lyakh, M Cardone, GM O'Connor, C Tan, H Li, SK Anderson, SA Jones, W Zhang, PR Taylor, G Trinchieri and DW McVicar: LAB/NTAL facilitates fungal/PAMP-induced IL-12 and IFN-gamma production by repressing beta-catenin activation in dendritic cells. PLoS Pathog 9, e1003357 (2013)

65. E Cenci, L Romani, A Vecchiarelli, P Puccetti and F Bistoni: T cell subsets and IFN-gamma production in resistance to systemic candidosis in immunized mice. J Immunol 144, 4333-4339 (1990)

66. L Romani, S Mocci, C Bietta, L Lanfaloni, P Puccetti and F Bistoni: Th1 and Th2 cytokine secretion patterns in murine candidiasis: association of Th1 responses with acquired resistance. Infect Immun 59, 4647-4654 (1991)

67. L Romani, A Mencacci, E Cenci, R Spaccapelo, P Mosci, P Puccetti and F Bistoni: CD4+ subset expression in murine candidiasis. Th responses correlate directly with genetically determined susceptibility or vaccine-induced resistance. $J$ Immunol 150, 925-931 (1993)

68. E Villamón, D Gozalbo, P Roig, C Murciano, JE O'Connor, D Fradelizi and ML Gil: Myeloid differentiation factor 88 (MyD88) is required for murine resistance to Candida albicans and is critically involved in Candida -induced production of cytokines. Eur Cytokine Netw 15, 263-271 (2004)

69. S Bellocchio, C Montagnoli, S Bozza, R Gaziano, G Rossi, SS Mambula, A Vecchi, A Mantovani, SM Levitz and L Romani: The contribution of the Toll-like/IL-1 receptor superfamily to innate and adaptive immunity to fungal pathogens in vivo. $J$ Immunol 172, 3059-3069 (2004)

70. MG Netea, NA Gow, LA Joosten, I Verschueren, JW van der Meer and BJ Kullberg: Variable recognition of Candida albicans strains by TLR4 and lectin recognition receptors. Med Mycol 48, 897-903 (2010)

71. E Villamón, D Gozalbo, P Roig, JE O'Connor, ML Ferrandiz, D Fradelizi and ML Gil: Toll-like receptor 2 is dispensable for acquired host immune resistance to Candida albicans in a murine model of disseminated candidiasis. Microbes Infect 6, 542-548 (2004)

72. C Murciano, E Villamón, D Gozalbo, P Roig, JE O'Connor and ML Gil: Toll-like receptor 4 defective mice carrying point or null mutations do not show increased susceptibility to Candida albicans in a model of hematogenously disseminated infection. Med Mycol 44, 149-157 (2006)

73. MG Netea, JW van der Meer and BJ Kullberg: Both TLR2 and TLR4 are involved in the recognition of Candida albicans. Reply to "TLR2, but not TLR4, triggers cytokine production by murine cells in response to Candida albicans yeasts and hyphae" by Gil and Gozalbo, Microbes and Infection 8, 2823-2824 (2006). Microbes Infect 8, 2821-2822 (2006)

74. ML Gil and D Gozalbo: Candida albicans, to be or not to be recognized by TLR4? Response to "Both TLR2 and TLR4 are involved in the recognition of Candida albicans" by M.G.Netea et al. Microb Infect 8, 2823-2824 (2006)

75. P Chiani, C Bromuro and A Torosantucci: Defective induction of interleukin-12 in human monocytes by germ-tube forms of Candida albicans. Infect Immun 68, 5628-5634 (2000)

76. CF d'Ostiani, G Del Sero, A Bacci, C Montagnoli, A Spreca, A Mencacci, P Ricciardi-Castagnoli and L Romani: Dendritic cells discriminate between yeasts and hyphae of the fungus Candida albicans. Implications for initiation of $\mathrm{T}$ helper cell immunity in vitro and in vivo. J Exp Med 191, 1661-1674 (2000)

77. L Liu, K Kang, M Takahara, KD Cooper and MA Ghannoum: Hyphae and yeasts of Candida albicans differentially regulate interleukin-12 production by human blood monocytes: inhibitory role of C. albicans germination. Infect Immun 69, $4695-4697$ (2001)

78. L Romani, C Montagnoli, S Bozza, K Perruccio, A Spreca, P Allavena, S Verbeek, RA Calderone, F Bistoni and P Puccetti: The exploitation of distinct recognition receptors in dendritic cells determines the full range of host immune relationships with Candida albicans. Int Immunol 16, 149-161 (2004) 
79. A Bacci, C Montagnoli, K Perruccio, S Bozza, R Gaziano, L Pitzurra, A Velardi, C. F d'Ostiani, JE Cutler and L Romani: Dendritic cells pulsed with fungal RNA induce protective immunity to Candida albicans in hematopoietic transplantation. $J$ Immunol 168, 2904-2913 (2002)

80. GD Brown: Dectin-1: a signalling non-TLR pattern-recognition receptor. Nat Rev Immunol 6, 33-43 (2006)

81. BN Gantner, RM Simmons, SJ Canavera, S Akira and DM Underhill: Collaborative induction of inflammatory responses by dectin-1 and Toll-like receptor 2. J Exp Med 197, 1107-1117 (2003)

82. BN Gantner, RM Simmons and DM Underhill: Dectin-1 mediates macrophage recognition of Candida albicans yeast but not filaments. EMBO J 24, 1277-1286 (2005)

83. SE Heinsbroek, GD Brown and S Gordon: Dectin-1 escape by fungal dimorphism. Trends Immunol 26, 352-354 (2005)

84. RT Wheeler, D Kombe, SD Agarwala and GR Fink: Dynamic, morphotype-specific Candida albicans beta-glucan exposure during infection and drug treatment. PLoS Pathog 4, e1000227 (2008)

85. W Huang, L Na, PL Fidel and P Schwarzenberger: Requirement of interleukin-17A for systemic anti-Candida albicans host defense in mice. $J$ Infect Dis 190, 624-631 (2004)

86. NW Palm and R Medzhitov: Antifungal defense turns 17. Nat Immunol 8, 549-551 (2007)

87. EV Acosta-Rodriguez, L Rivino, J Geginat, D Jarrossay, M Gattorno, A Lanzavecchia, F Sallusto and G Napolitani: Surface phenotype and antigenic specificity of human interleukin 17-producing T helper memory cells. Nat Immunol 8, 639-646 (2007)

88. S LeibundGut-Landmann, O Gross, MJ Robinson, F Osorio, EC Slack, SV Tsoni, E Schweighoffer, V Tybulewicz, GD Brown, J Ruland and C Reis e Sousa: Syk- and CARD9-dependent coupling of innate immunity to the induction of T helper cells that produce interleukin 17. Nat Immunol 8, 630-638 (2007)

89. A De Luca, T Zelante, C D'Angelo, S Zagarella, F Fallarino, A Spreca, RG Iannitti, P Bonifazi, JC Renauld, F Bistoni, P Puccetti and L Romani: IL-22 defines a novel immune pathway of antifungal resistance. Mucosal Immunol 3, 361-373 (2010)

90. FL van de Veerdonk, BJ Kullberg, IC Verschueren, T Hendriks, JW van der Meer, LA Joosten and MG Netea: Differential effects of IL-17 pathway in disseminated candidiasis and zymosan-induced multiple organ failure. Shock 34, 407-411 (2010)

91. W Haas, P Pereira and S Tonegawa: Gamma/delta cells. Annu Rev Immunol 11, 637-685 (1993)

92. D Fenoglio, A Poggi, S Catellani, F Battaglia, A Ferrera, M Setti, G Murdaca and MR Zocchi: Vdelta1 T lymphocytes producing IFN-gamma and IL-17 are expanded in HIV-1-infected patients and respond to Candida albicans. Blood 113, 66116618 (2009)

93. J Jones-Carson, A Vazquez-Torres, HC van der Heyde, T Warner, RD Wagner and E Balish: Gamma delta T cell-induced nitric oxide production enhances resistance to mucosal candidiasis. Nat Med 1, 552-557 (1995)

94. J Jones-Carson, A Vazquez-Torres, T Warner and E Balish: Disparate requirement for T cells in resistance to mucosal and acute systemic candidiasis. Infect Immun 68, 2363-2365 (2000)

95. A Poggi, S Catellani, A Musso and MR Zocchi: Gammadelta T lymphocytes producing IFNgamma and IL-17 in response to Candida albicans or mycobacterial antigens: possible implications for acute and chronic inflammation. Curr Med Chem 16, 4743-4749 (2009)

96. MS Renna, CM Figueredo, MC. Rodriguez-Galan, PA Icely, JM Peralta Ramos, SG Correa and CE Sotomayor: Abrogation of spontaneous liver tolerance during immune response to Candida albicans: contribution of NKT and hepatic mononuclear cells. Int Immunol 24, 315-325 (2012)

97. NR Cohen, RV Tatituri, A Rivera, GF Watts, EY Kim, A Chiba, BB Fuchs, E Mylonakis, GS Besra, SM Levitz, M Brigl and MB Brenner: Innate recognition of cell wall beta-glucans drives invariant natural killer T cell responses against fungi. Cell Host Microbe 10, 437-450 (2011)

98. M Prlic and TM Hohl: iNKTs foil fungi. Cell Host Microbe 10, 421-422 (2011) 
99. N Tarumoto, Y Kinjo, N Kitano, D Sasai, K Ueno, A Okawara, Y Izawa, M Shinozaki, H Watarai, M Taniguchi, H Takeyama, S Maesaki, K Shibuya and Y Miyazaki: Exacerbation of Invasive Candida albicans Infection by Commensal Bacteria or a Glycolipid Through IFN-gamma Produced in Part by iNKT Cells. J Infect Dis 209, 799-810 (2014)

100. RB Ashman, A Fulurija and JM Papadimitriou: Both CD4+ and CD8+ lymphocytes reduce the severity of tissue lesions in murine systemic cadidiasis, and CD4+ cells also demonstrate strain-specific immunopathological effects. Microbiology 145, 1631-1640 (1999)

101. M Wuthrich, HI Filutowicz, T Warner, GS Deepe, Jr. and BS Klein: Vaccine immunity to pathogenic fungi overcomes the requirement for CD4 help in exogenous antigen presentation to CD8+ T cells: implications for vaccine development in immunedeficient hosts. J Exp Med 197, 1405-1416 (2003)

102. E Balish, FA Vazquez-Torres, J Jones-Carson, RD Wagner and T Warner: Importance of beta2-microglobulin in murine resistance to mucosal and systemic candidiasis. Infect Immun 64, 5092-5097 (1996)

103. JA Winkelstein, MC Marino, RB Johnston, Jr., J Boyle, J Curnutte, JI Gallin, HL Malech, SM Holland, H Ochs, P Quie, R H. Buckley, CB Foster, SJ Chanock and H Dickler: Chronic granulomatous disease. Report on a national registry of 368 patients. Medicine, 79, 155-169 (2000)

104. BH Segal, J Kwon-Chung, TJ Walsh, BS Klein, M Battiwalla, NG Almyroudis, SM Holland and L Romani: Immunotherapy for fungal infections. Clin Infect Dis 42, 507-515 (2006)

105. L Tramsen, O Beck, FR Schuster, KP Hunfeld, JP Latge, J Sarfati, F Roger, T Klingebiel, U Koehl and T Lehrnbecher: Generation and characterization of anti-Candida $\mathrm{T}$ cells as potential immunotherapy in patients with Candida infection after allogeneic hematopoietic stem-cell transplant. J Infect Dis 196, 485-492 (2007)

106. RG Iannitti, A Carvalho and L Romani: From memory to antifungal vaccine design. Trends Immunol 33, 467-474 (2012)

107. E Paulovicova, L Paulovicova, R Pilisiova, S Bystricky, DV Yashunsky, AA Karelin, YE Tsvetkov and NE Nifantiev: Synthetically prepared glycooligosaccharides mimicking Candida albicans cell wall glycan antigens - novel tools to study hostpathogen interactions. FEMS Yeast Res 13, 659-673 (2013)

108. SP Smeekens, A Ng, Kumar, MD Johnson, TS Plantinga, C van Diemen, P Arts, ET Verwiel, MS Gresnigt, K Fransen, S van Sommeren, M Oosting, SC Cheng, LA Joosten, A Hoischen, BJ Kullberg, WK Scott, JR Perfect, JW van der Meer, C Wijmenga, MG Netea and RJ Xavier: Functional genomics identifies type I interferon pathway as central for host defense against Candida albicans. Nat Commun 4, 1342 (2013)

109. C Bourgeois, O Majer, IE Frohner, I Lesiak-Markowicz, KS Hildering, W Glaser, S Stockinger, T Decker, S Akira, M Muller and K Kuchler: Conventional dendritic cells mount a type I IFN response against Candida spp. requiring novel phagosomal TLR7-mediated IFN-beta signaling. J Immunol 186, 3104-3112 (2011)

110. C del Fresno, D Soulat, S Roth, K Blazek, I Udalova, D Sancho, J Ruland and C Ardavin: Interferon-beta production via Dectin-1-Syk-IRF5 signaling in dendritic cells is crucial for immunity to C. albicans. Immunity 38, 1176-1186 (2013)

Key Words: Candida albicans, Candidiasis, Infection, IFN-gamma, Review

Send correspondence to: M. Luisa Gil, Departamento de Microbiología y Ecología, Universitat de València, Edificio de Investigacion, Dr. Moliner, 50, 46100 Burjassot, Valencia, Spain, Tel: 34-963543410, Fax: 34-963544570, E-mail: m.luisa.gil@uv.es

Running title: IFN- $\gamma$ in Candida albicans infections 